\title{
Gastrointestinal mucormycosis in a renal transplant patient
}

\author{
Jill Tinmouth MD FRCPC ${ }^{1}$, Jeffrey Baker MD FRCPC ${ }^{1,2}$, Geoffrey Gardiner MD FRCPC ${ }^{3}$
}

\begin{abstract}
J Tinmouth, J Baker, G Gardiner. Gastrointestinal mucormycosis in a renal transplant patient. Can J Gastroenterol 2001;15(4):269-271. The clinical course and management of a rare case of gastrointestinal mucormycosis occurring in a renal transplant patient are presented. The diagnosis was made on pathological examination of surgically resected tissue from the colon, spleen and stomach. The patient did not survive the infection. To the best of our knowledge, this is the 11 th reported case of gastrointestinal mucormycosis in a solid organ transplant patient. The pathophysiology, incidence and prognosis of this disease are discussed.
\end{abstract}

Key Words: Diabetes; Gastrointestinal disease; Immunosuppression; Mucormycosis; Renal allograft; Transplantation

\section{Mucormycose gastro-intestinale chez un receveur de greffe rénale}

RÉSUMÉ : On présente ici l'évolution clinique et le traitement d'un cas rare de mucormycose gastro-intestinale chez un receveur de greffe rénale. Le diagnostic a été posé à partir d'un examen pathologique des tissus réséqués chirurgicalement au niveau du côlon, de la rate et de l'estomac. Le patient n'a pas survécu à l'infection. À notre connaissance, il s'agit du onzième cas rapporté de mucormycose gastro-intestinale dans un organe solide chez un receveur de greffe. La physiopathologie, l'incidence et le pronostic de cette maladie sont abordées. lthough it is relatively uncommon, mucormycosis, a
fungus of the order Mucorales, may cause opportunistic
infection in patients with diabetic ketoacidosis and neo-
plastic diseases, and in patients who have undergone organ
transplantation. The present report describes a rare case of
gastrointestinal mucormycosis in a renal transplant patient.

\section{CASE PRESENTATION}

A 57-year-old man, who had undergone cadaveric renal transplantation for end-stage renal disease secondary to hypertension two months earlier, presented with complaints of generalized abdominal pain, distention and constipation. Acetominophen with codeine had recently been started for pleuritic chest pain secondary to Escherichia coli pneumonia.
At renal transplantation, the patient was initially immunosuppressed with cyclosporine and steroids. However, acute rejection developed requiring high dose pulse steroids and thyroglobulin infusion. Antilymphocyte globulin was not used. The immunosuppressive agents were changed to tacrolimus, prednisone and mycophenolate mofetil (MMF). Steroid-induced diabetes, controlled by oral hypoglycemic agents, developed after this regimen was instituted. One week before admission, the MMF was stopped because of gastrointestinal complaints.

Past medical history also included hypertension and noncirrhotic hepatitis C. On admission, medications included ciprofloxacin, clarithromycin, tacrolimus $4 \mathrm{mg}$ every $12 \mathrm{~h}$, prednisone $15 \mathrm{mg} /$ day, glyburide, diltiazem hydrochloride

${ }^{1}$ Department of Medicine, University of Toronto; ${ }^{2}$ Department of Gastroenterology, St Michael's Hospital; Department of Pathology, University of Toronto, Toronto, Ontario

Correspondence and reprints: Dr Jeffrey Baker, Department of Gastroenterology, St Michael's Hospital, 30 Bond Street, B Wing, Toronto,

Ontario M5B 1W8. Telephone 416-864-5909, fax 416-864-5995, e-mail bakerj@smh.toronto.on.ca

Received for publication October 19, 1999. Accepted January 25, 2000 


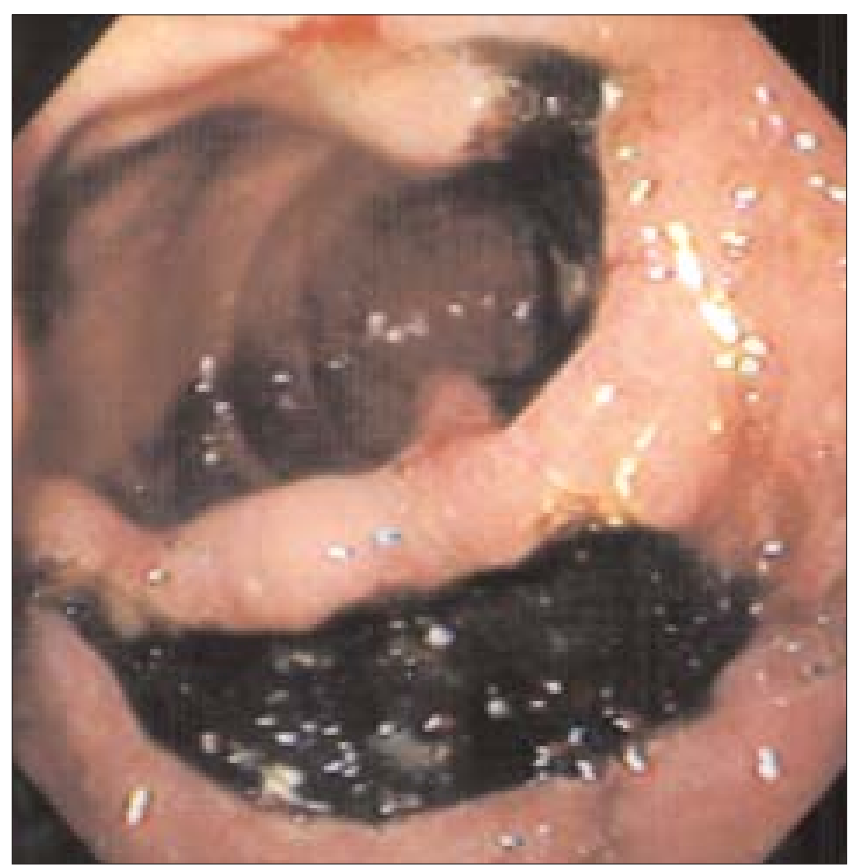

Figure 1) Endoscopic image of two duodenal ulcers seen in the index patient. The extremely black, necrotic centres are typical of ulceration secondary to mucormycosis

(Cardizem, Aventis Pharmaceuticals, Canada) and acebutolol.

Initial investigations revealed a white blood cell count of $7.2 \times 10^{9} / \mathrm{L}$, a hemoglobin concentration of $97 \mathrm{~g} / \mathrm{L}$ and a platelet count of $153 \times 10^{9} / \mathrm{L}$. Random blood sugar concentration was $4.6 \mathrm{mmol} / \mathrm{L}$. Creatinine was 160 , unchanged after transplantation. Plain films of the abdomen showed mild dilation of the large bowel, a few air-fluid levels, air in the rectum, and stool in the ascending and transverse colon. The abdominal complaints were attributed to constipation secondary to the codeine, and laxative treatment was undertaken. At admission, the patient's tacrolimus concentrations were elevated at $18.8 \mu / \mathrm{L}$; the concentrations fell into the target range ( 10 to $15 \mu \mathrm{g} / \mathrm{L}$ ) within two days without adjusting the tacrolimus dose.

The gastrointestinal symptoms persisted and colonoscopy was performed but failed to show pathology. The patient underwent gastroscopy several days later, and two large duodenal ulcers (Figure 1) and one large gastric ulcer (located in the body) were seen. The ulcers had elevated mucosa at the margins and black, necrotic centres. Mucosal biopsies revealed nonspecific ulceration.

During hospitalization, the patient had daily spiking fevers, and pulmonary Aspergillus fumigatus was diagnosed by sputum culture. Itraconazole was started and was subsequently changed to amphotericin B. While on itraconazole, tacrolimus concentrations rose significantly to $27.5 \mu \mathrm{g} / \mathrm{L}$ and the tacrolimus was held. The concentrations normalized within several days.

The fevers continued and the patient's white cell count climbed to $51.6 \times 10^{9} / \mathrm{L}$. Abdominal computer-assisted tomography (CAT) scan revealed a splenic abscess. Despite

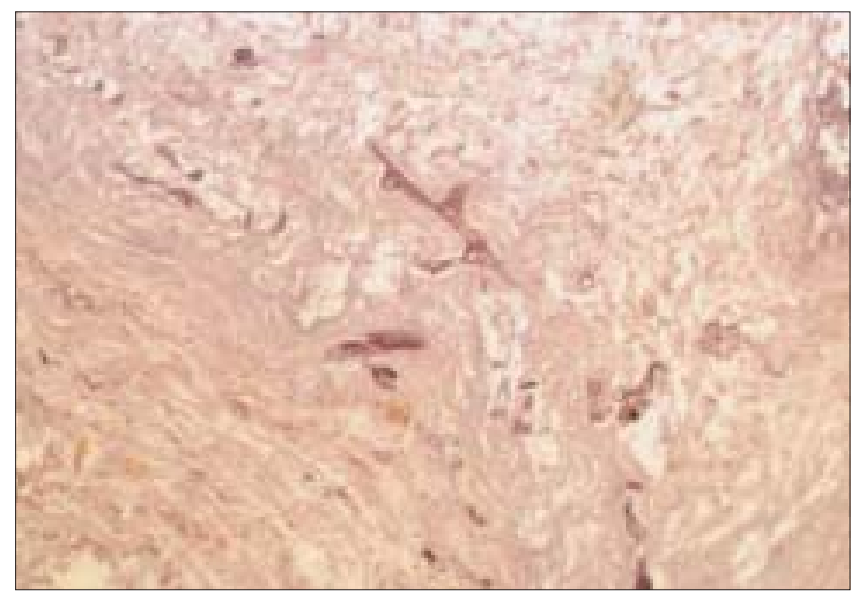

Figure 2) High power view of gastric tissue containing an invading Rhizopus organism. Note the broad nonseptate branching morphology that is characteristic of mucor (hematoxylin and eosin stain, original magnification $\times 40$ )

percutaneous catheter drainage, the patient's condition worsened clinically and he was taken to the operating room for splenectomy.

Operative findings were more extensive than those from the CAT imaging. Widespread necrosis was found encompassing the spleen, the fundus of the stomach, the diaphragm, the splenic flexure and the descending colon. The affected areas were debrided. Pathological examination of the resected stomach revealed ulceration and vascular invasion by abundant, broad, nonseptate, irregularly branching hyphae (Figure 2) consistent with mucormycosis. These fungi were culture-confirmed on blood and Sabouraud agar plates as Rhizopus rhizopodiformis. Despite having all immunosuppressive medications withheld and being treated aggressively surgically and with amphotericin $\mathrm{B}$, the patient became progressively more septic and died eight days after surgery.

\section{DISCUSSION}

Although mucormycosis is commonly found in soil and decaying organic matter, including food, clinical infection is rare. Therefore, host factors are critical determinants of disease. Immunocompromised patients, such as transplant recipients, patients with lymphoproliferative disorders and diabetic patients, are particularly susceptible. Predisposing factors in our patient included immunosuppression and possibly diabetes and hemodialysis. In mice infected with Absidia species, a member of the mucor family, cortisone increased susceptibility to infection and promoted disseminated infection, while azathioprine, cyclophosphamide and antithymocyte serum did not (1). In a review of transplant recipients infected with mucor, $76 \%$ received augmented immunosuppression, like the patient in the present case, mainly in the form of corticosteroids (2). During hospitalization, the patient's tacrolimus concentrations were elevated on several occasions, likely secondary to the interaction with clarithromycin and itraconazole $(3,4)$; however, the clinical importance of these elevated concen- 
trations on the acquisition and course of his infection is unclear.

Infection occurs through the ingestion or inhalation of spores. Disruption of the mucosal barrier, such as that seen in peptic ulcer disease, may be important in the pathogenesis of gastric mucor (5). Alternatively, disseminated infection from vascular invasion can be considered as another pathogenic mechanism. In the present patient, mucor invaded the gastric and duodenal wall, creating the ulcerations seen at gastroscopy. The pathology showed angioinvasion with ischemic necrosis and fungal colonization of spleen, colon and diaphragm. While the present patient also had an infection with Aspergillus species, the morphology of these two organisms is quite distinct, enabling them to be easily distinguished on routine microscopic examination of cultures or pathological specimens.

Mucor thrives in environments rich in iron, suggesting that this element may be necessary for fungal growth and infection. It has been elegantly shown that acidosis, such as that which occurs in poorly controlled diabetic patients, both promotes the growth of Rhizopus species and increases available free iron by reducing its binding affinity for transferrin (6). A registry of patients on hemodialysis with documented mucor infection showed that $78 \%$ had received deferoxamine, an iron chelator, for the treatment of iron or aluminum overload. The chelated form of iron is more easily taken up by mucor, and guinea pigs exposed to deferoxamine are more susceptible to infection with Rhizopus (7). The present patient was neither exposed to deferoxamine nor was he ketoacidotic at the time of presentation; however, diabetes and hemodialysis alone may also be lesser risk factors for mucormycosis.

The majority of mucormycosis infections are pulmonary or rhinocerebral. Other forms of the disease include cuta-

\section{REFERENCES}

1. Corbel MJ, Eades SM. Factors determining the susceptibility of mice to experimental phycomycosis. J Med Microbiol 1975;8:551-64.

2. Singh N, Gayowski T, Singh J, Yu VL. Invasive gastrointestinal zygomycosis in a liver transplant recipient: Case report and review of zygomycosis in solid-organ transplant recipients. Clin Infect Dis 1995;20:617-20.

3. Furlan V, Parquin F, Penaud JF, et al. The interaction between tacrolimus and itraconzale in a heart-lung transplant recipient. Transplant Proc 1998;30:187-8.

4. Mignat C. Clinically significant drug interactions with new immunosuppressive agents. Drug Saf 1997;16:267-78.

5. Thomson SR, Bade PG, Taams M, Chrystal V. Gastrointestinal mucormycosis. Br J Surg 1991;78:952-4.

6. Artis WM, Fountain JA, Delcher HK, Jones HE. A mechanism of susceptibility to mucormycosis in diabetic ketoacidosis: Transferrin and iron availability. Diabetes 1982;31:1109-14.

7. Boelaert JR, de Locht M, Van Cutsem J, et al. Mucormycosis during deferoxamine therapy is a siderophore-mediated infection: In vitro and in vivo animal studies. J Clin Invest 1993;91:1979-86.

8. Lyon DT, Schubert TT, Mantia AG, Kaplan MH. Phycomycosis of the gastrointestinal tract. Am J Gastroenterol 1979;72:379-94.

9. Cherney CL, Chutuape A, Fikrig MK. Fatal invasive gastric mucormycosis occuring with emphysematous gastritis: Case report and literature review. Am J Gastroenterol 1999;94:252-6.

10. Parfrey NA. Improved diagnosis and prognosis of mucormycosis. neous, isolated neurological, gastrointestinal and disseminated infections. Gastrointestinal mucor is a rare entity, accounting for only $7 \%$ of all cases of mucormycosis. The stomach is the most common site of gastrointestinal infection, followed by the colon and small bowel (8). Endoscopically, mucormycosis presents as a shaggy, velvety and discoloured mucosa or, as in the present case, as giant ulcers with necrotic, black centres. Biopsies from the centre of the ulcer are thought to be more diagnostic than ulcer margin biopsies. Tissue necrosis associated with mucor is also a substrate for secondary bacterial infection and recently, a case of emphysematous gastritis associated with invasive mucormycosis was reported (9).

In recent years, the prognosis of mucormycosis has improved, but the overall mortality rate of $27 \%$ remains significant (10). Solid organ transplant patients tend to do worse, having a reported mortality of $56 \%$ for all forms of mucor (2). Patients with invasive gastrointestinal disease have a poor outcome, with mortality ranging from $46 \%$ to 98\% $(5,8)$. We reviewed the literature using Grateful Med and the search terms, 'gastrointestinal disease', 'mucormycosis' and 'transplantation'. Including the present case, there were 11 cases of gastrointestinal mucor in organ transplantation patients in the literature. Of these patients, five (45\%) survived (11-15) and six (55\%) died, including the patient in the present case $(2,12,16-18)$.

Outcomes from mucormycosis have improved since the 1970s (10). This is attributable to earlier diagnosis leading to aggressive and early surgical debridement with adjunct amphotericin B treatment. Gastroenterologists must have a high index of suspicion for mucormycosis when evaluating gastrointestinal ulcers in susceptible patients such as organ transplant recipients so that appropriate interventions may be instituted early in the course of the illness.

Medicine 1986;65:113-23.

11. Martinez EJ, Cancio MR, Sinnott JT, Vincent AL, Brantley SG. Nonfatal gastric mucormycosis in a renal transplant recipient. South Med J 1997;90:341-4.

12. Knoop C, Antoine M, Vachiery JL, et al. Gastric perforation due to mucormycosis after heart-lung and heart transplantation. Transplantation 1998;66:932-5.

13. Corley DA, Lindeman N, Ostroff JW. Survival with early diagnosis of invasive gastric mucormycosis in a heart transplant patient. Gastrointest Endosc 1997;46:452-4.

14. Winkler S, Susani S, Willinger B et al. Gastric mucormycosis due to Rhizopus oryzae in a renal transplant recipient. J Clin Microbiol 1996;34:2585-7.

15. Jorgensen PF, Brekke IB, Bakka A, Claussenn OP. Severe mucormycosis after organ transplantation. Report of a case. Tidsskr Nor Laegerforen 1995;115:2392-4.

16. Sheu BS, Lee PC, Yang HB. A giant gastric ulcer caused by mucormycosis infection in a patient with renal transplantation. Endoscopy 1998;30:S60-1.

17. Barroso F, Forcelledo JL, Mayorga M, Pena F, Marques FF, de la Pena J. A fatal case of gastric mucormycosis in a heart transplant recipient. Endoscopy 1999;31:S2.

18. Mazza D, Gugenheim J, Baldini E, Mouiel J. Gastrointestinal mucormycosis and liver transplantation; a case report and review of the literature. Transpl Int 1999;12:297-8. 


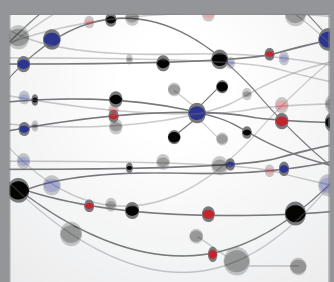

The Scientific World Journal
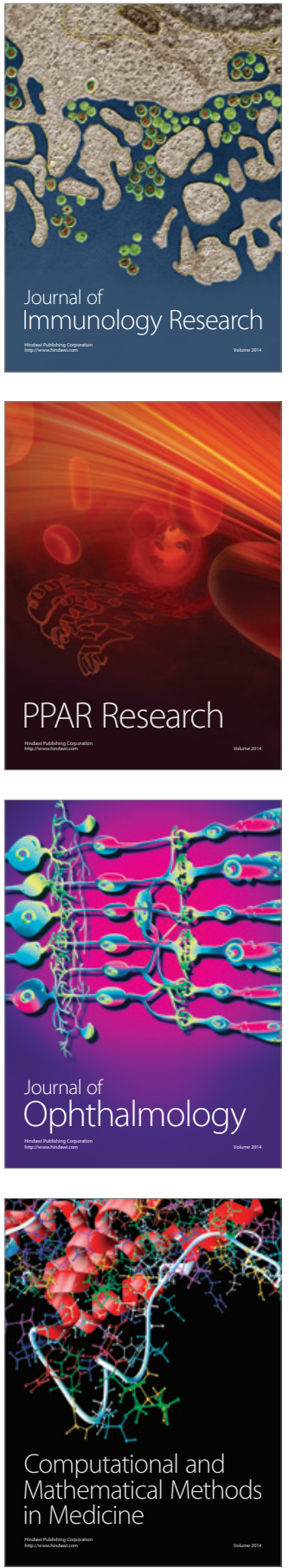

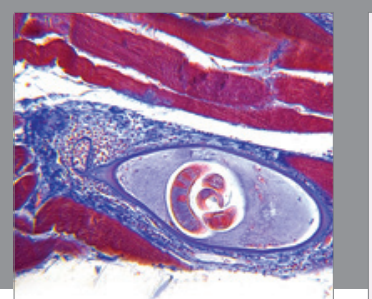

Gastroenterology Research and Practice

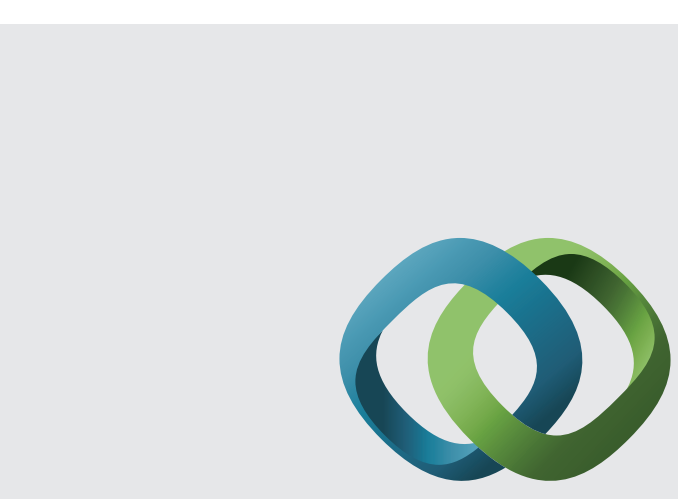

\section{Hindawi}

Submit your manuscripts at

http://www.hindawi.com
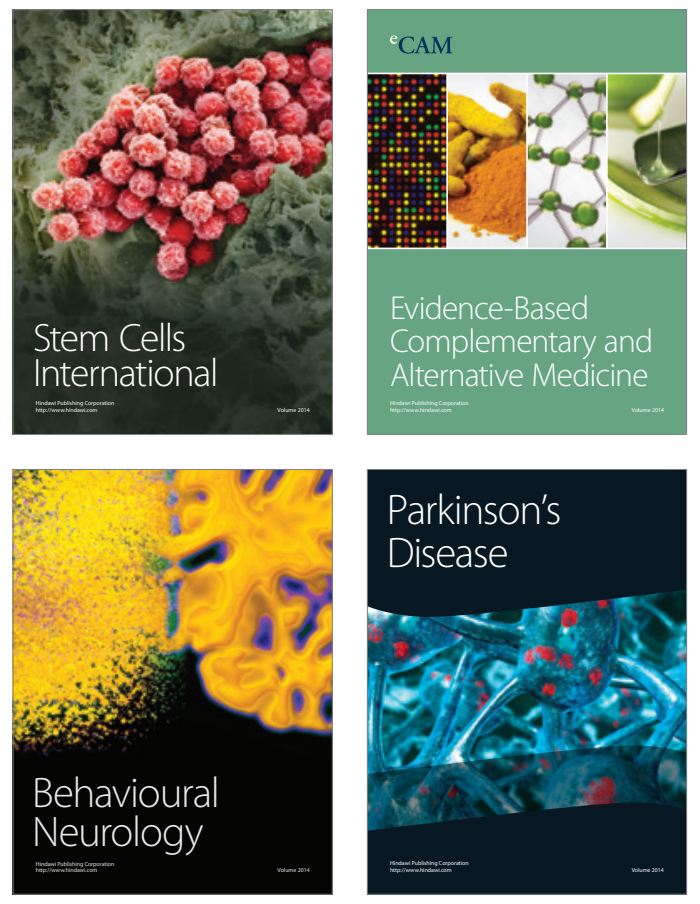
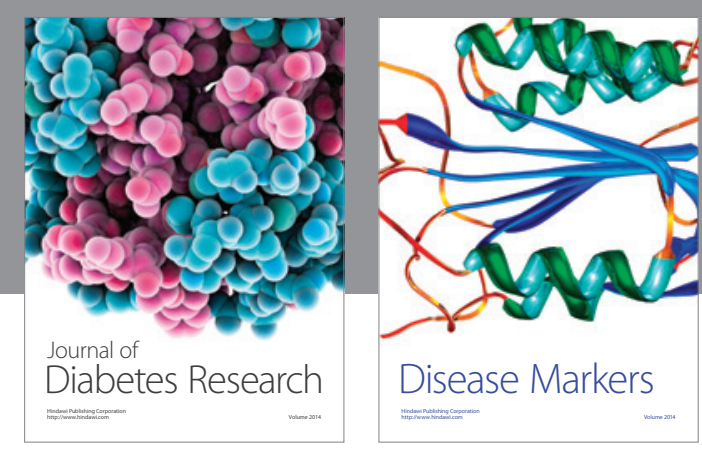

Disease Markers
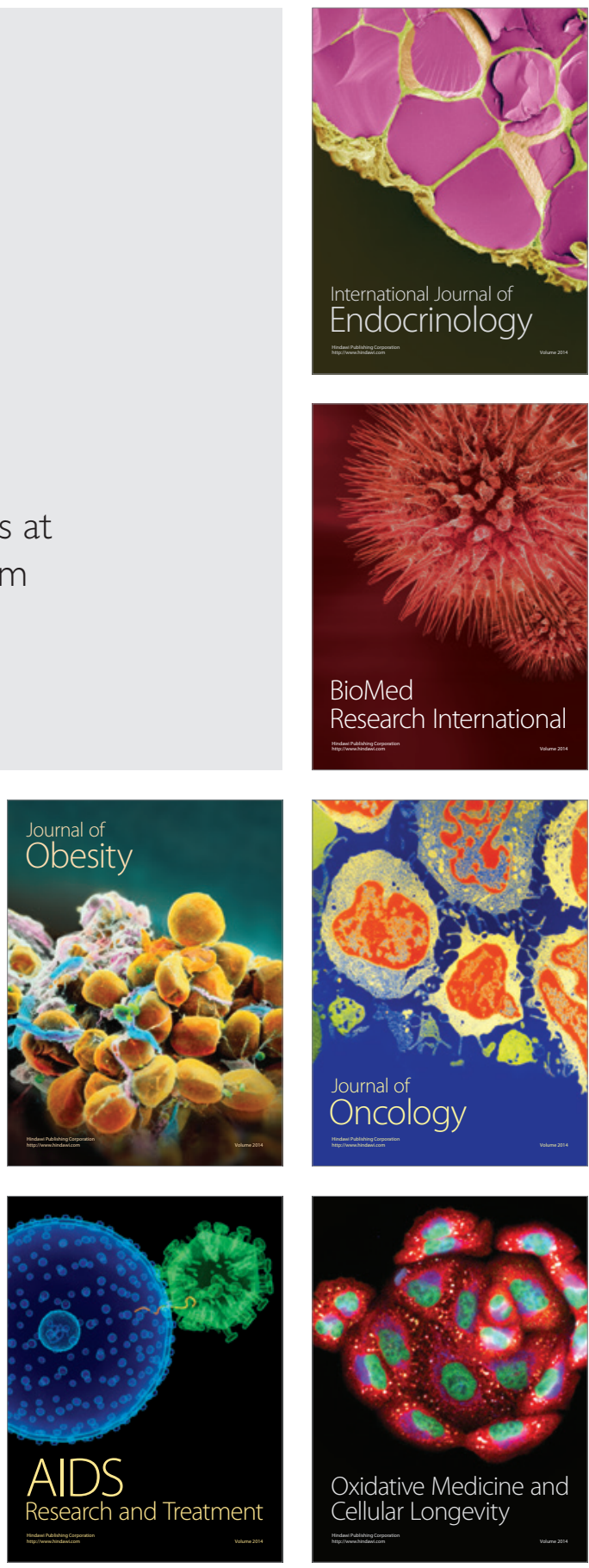